\title{
$\beta$-Blockers, heart disease and COPD: current controversies and uncertainties
}

\author{
Jillian G Baker, ${ }^{1}$ Robert G Wilcox ${ }^{2}$
}

${ }^{1}$ Respiratory Medicine, Cell Signalling, School of Life Sciences, University of Nottingham, Nottingham, UK 2Department of Clinical Neurosciences, Queen's Medical Centre, University of Nottingham, Nottingham, UK

\section{Correspondence to} Professor Jillian G Baker, Respiratory Medicine, Cell Signalling, School of Life Sciences, C Floor Medical School, Queen's Medical Centre, University of Nottingham, Nottingham NG11 2UH, UK. jillian.baker@nottingham.ac.uk

Received 10 May 2016 Revised 14 October 2016 Accepted 21 October 2016 Published Online First 7 December 2016

\begin{abstract}
Treating people with cardiovascular disease and COPD causes significant clinician anxiety. $\beta$-Blockers save lives in people with heart disease, specifically postinfarction and heart failure. COPD and heart disease frequently coexist and people with both disorders have particularly high cardiovascular mortality. There are concerns about giving $\beta$-blockers to people with concomitant COPD that include reduced basal lung function, diminished effectiveness of emergency $\beta$-agonist treatments, reduced benefit of long-acting $\beta$-agonist treatment and difficulty in discriminating between asthma and COPD. $\beta$-Blockers appear to reduce lung function in both the general population and those with COPD because they are poorly selective for cardiac $\beta 1$-adrenoceptors over respiratory $\beta 2$-adrenoceptors, and studies have shown that higher $\beta$-agonist doses are required to overcome the $\beta$-blockade. COPD and cardiovascular disease share similar environmental risks and both disease states have high adrenergic and inflammatory activation. $\beta$-Blockers may therefore be particularly helpful in reducing cardiovascular events in this high-risk group. They may reduce the background inflammatory state, and inhibit the tachycardia and hypertension associated with both the endogenous adrenaline and high-dose $\beta$-agonist treatment associated with acute exacerbations of COPD. Some studies have suggested no increased and, at times, reduced mortality in patients with COPD taking $\beta$-blockers for heart disease. However, these are all observational studies and there are no randomised controlled trials. Potential ways to improve this dilemma include the development of highly $\beta 1$-selective $\beta$-blockers or the use of non- $\beta$-blocking heart rate reducing agents, such as ivabridine, if these are proven to be beneficial in randomised controlled trials.
\end{abstract}

$\beta$-Blockers save lives in people with cardiovascular disease. They reduce mortality in patients with heart failure and postmyocardial infarction (MI). $\beta$-Blockers are also first-line therapy for several atrial arrhythmias, are important in managing symptoms in patients with angina and in the treatment of hypertension, thyrotoxicosis, portal hypertension, migraine, glaucoma and anxiety. However, there is significant theoretical and clinical concern about giving $\beta$-blockers to patients with cardiovascular disease who also have obstructive lung disease. This review focuses on the dilemma of using $\beta$-blockers in people with COPD and heart disease, but it is important to remember this dilemma extends to those with peripheral vascular disease (in whom $\beta$-blockade can worsen limb ischaemia) and those with asthma (in whom $\beta$-blockade can be life-threatening). This review does not address the issue of $\beta$-blockers in people with asthma, in whom $\beta$-blockers remain contraindicated (section 7.11.7 ${ }^{1}$ ).

\section{CHRONIC OBSTRUCTIVE PULMONARY DISEASE}

In England, the Department of Health estimates that 3.2 million people have COPD and $40 \%$ of these patients also have heart disease, ${ }^{2}$ especially heart failure. ${ }^{3} 4$ People with COPD and heart disease have a particularly high risk of death from heart disease and stroke (2-5 times higher than those with heart disease alone ${ }^{5}{ }^{6}$ ). As $\beta$-blockade is highly desirable in this high-risk group, it is therefore very important to sort out the thorny issue of whether any, some or all of these patients can be given a $\beta$-blocker and how this can be safely achieved in everyday clinical practice and not just within a carefully monitored study population.

The definition of COPD includes 'airflow limitation that is not fully reversible'. 7 Theoretically, patients with COPD have significant fixed, irreversible airways obstruction and therefore little reversibility and so $\beta$-blockade should pose no risk. Global initiative for chronic obstructive lung disease $(\mathrm{GOLD})^{7}$ recommend that ideally the obstruction should be measured postbronchodilator (in order to truly assess the degree of 'fixed' obstruction), although for practical reasons this is not always followed in the real world. The problem is that possibly half of patients with a diagnosis of COPD have some significant reversibility and up to $50 \%$ of patients change from being 'irreversible' to 'reversible' between visits, making it difficult for the clinician to be certain of a real 'fixed' component. ${ }^{8-10}$

Traditionally reversibility has been defined as $>12 \%$ improvement, or $200 \mathrm{~mL}$ increase, in $\mathrm{FEV}_{1}$. However, the American Thoracic Society/European Respiratory Society (ATS/ERS) Task Force concluded that for COPD, a $100 \mathrm{~mL}$ change in $\mathrm{FEV}_{1}$ was clinically significant and a 5\%-10\% change from baseline clinically important. ${ }^{11}$ Furthermore, $\beta 2$-agonists are the mainstay of treatment in COPD and have been proven to improve lung function, breathlessness and quality of life, and to reduce the exacerbation rate (many studies including ${ }^{12-14}$ ).

\section{$\beta$-BLOCKERS}

$\beta$-Blockers were developed by Sir James Black in the 1960 s for the treatment of hypertension and angina $^{15}$ and there are now many different $\beta$-blockers available for use in patients. $\beta$-Blockers primarily have their beneficial effects by blocking the $\beta 1$-adrenoceptors in the heart ${ }^{14}$ and thus preventing the action of endogenous catecholamines adrenaline and noradrenaline. Therefore, $\beta$-blockade 
results in a reduction in both the rate and force of contraction and thus a reduction in myocardial demand and, beyond doubt, reduce mortality in heart disease (table 1). ${ }^{16-20}$

In patients with heart failure, randomised placebo-controlled trials have demonstrated a $34 \%-35 \%$ reduction in mortality (metoprolol, ${ }^{21}$ bisoprolol, ${ }^{22}$ carvedilol $^{23}$ ). A further $\beta$-blocker, nebivolol, was found useful in elderly patients. ${ }^{24}$ However, $\beta$-blockers are not a single entity and differ, among other properties, in their receptor selectivity (between $\beta 1$-adrenoceptors and $\beta 2$-adrenoceptors) and in the extent of intrinsic sympathomimetic activity (ISA, or partial agonism). In heart failure, the two studies that examined $\beta$-blockers with ISA, were found to be not beneficial (bucindolol ${ }^{25}$ ) or actually increased mortality $\left(x^{x a m o t e r o l}{ }^{26}\right)$. In ischaemic heart disease, a variety of $\beta$-blockers without ISA reduced mortality during the acute MI period (usually taken as 2 years), for example, timolol by $39 \%,{ }^{27}$ propranolol by $26 \%{ }^{28}$ and metoprolol by $36 \%,{ }^{29}$ whereas trials with $\beta$-blockers with ISA (eg, oxprenolol and pindolol) did not show beneficial effects. ${ }^{30-33}$

Although $\beta 1$-adrenoceptors predominate, the human heart also has a small proportion of $\beta 2$-adrenoceptors. ${ }^{34}{ }^{35}$ Animal studies have suggested that long-term activation of $\beta 1$-adrenoceptors has more marked deleterious effects than activation of $\beta 2$-adrenoceptors, ${ }^{36}$ and the beneficial effects of $\beta$-blockers are therefore attributed to $\beta 1$-blockade. ${ }^{16}$

The $\beta$-adrenoceptor present in the lungs is the $\beta 2$-adrenoceptor. Stimulation of these $\beta 2$-adrenoceptors results in bronchodilation and this has been the mainstay of treatment for both short-term rescue and long-term maintenance in patients with asthma and COPD for decades. ${ }^{37}$ Current $\beta$-blockers are poorly selective for the cardiac $\beta 1$-receptors over the respiratory $\beta 2$-receptors. ${ }^{38-41}$ Even those considered 'cardioselective' are actually poorly $\beta 1$-selective, with a $\beta 1$-selectivity of only 13 -fold to 19 -fold (eg, bisoprolo ${ }^{38-40}$ ). To put this in context, the $\beta 2$-agonist salmeterol has a $\beta 2$-selectivity of
1000-3000 over the $\beta 1$-adrenoceptor, and commonly used laboratory antagonists are about 500 -fold selective for their respective $\beta 1$-adrenoceptor or $\beta 2$-adrenoceptor subtypes. Thus, current $\beta$-blockers available for clinical use, even those considered to be the most cardioselective, can cause the $\beta 2$-mediated respiratory side effects of bronchospasm or a fall in $\mathrm{FEV}_{1}$ in susceptible individuals. $^{42}$

\section{THEORETICAL AND CLINICAL STUDY CONCERNS OF $\beta$-BLOCKERS IN COPD}

There are several theoretical concerns over giving $\beta$-blockers to patients with COPD. First, a $\beta$-blocker may reduce the patient's basal (stable) $\mathrm{FEV}_{1}$, and in severe disease, even a small decrease in lung function could have a major impact on symptoms. Second, a $\beta$-blocker would diminish the response to rescue $\beta 2$-agonist therapy. Thus, during an acute exacerbation a $\beta$-blocked patient may have a lack or diminished response to important and potential life-saving $\beta 2$-agonist rescue therapy. This would occur even if the $\beta$-blocker is well tolerated while the patient was stable. Third, there is concern that the long-term co-administration of a $\beta$-blocker would block or reduce the long-term beneficial effects reported with long-acting $\beta 2$-agonist therapy (table 2).

Several clinical studies have shown that $\beta$-blockers do reduce $\mathrm{FEV}_{1}$. In a recent large general population study, non-selective $\beta$-blockers reduced $\mathrm{FEV}_{1}$ by $198 \mathrm{~mL}$ and 'cardioselective' $\beta$-blockers by $118 \mathrm{~mL},{ }^{43}$ that is, above the ATS/ERS Task Force ceiling of $100 \mathrm{~mL}$ change in $\mathrm{FEV}_{1}$ being clinically significant in COPD. This population included people with asthma and COPD. If these people (ie, those at high risk of bronchospasm) were excluded, the reduction in $\mathrm{FEV}_{1}$ was still over $100 \mathrm{~mL}$, even with 'cardioselective' $\beta$-blockers. Furthermore in the general population, $\mathrm{FEV}_{1}$ increased in those who stopped taking $\beta$-blockers during the study. Other studies in patients with COPD report $a$ fall in lung function and wheeze with

Table 1 Overview of effects of $\beta$-agonists and $\beta$-blockers on organs relevant to cardiovascular and respiratory disease

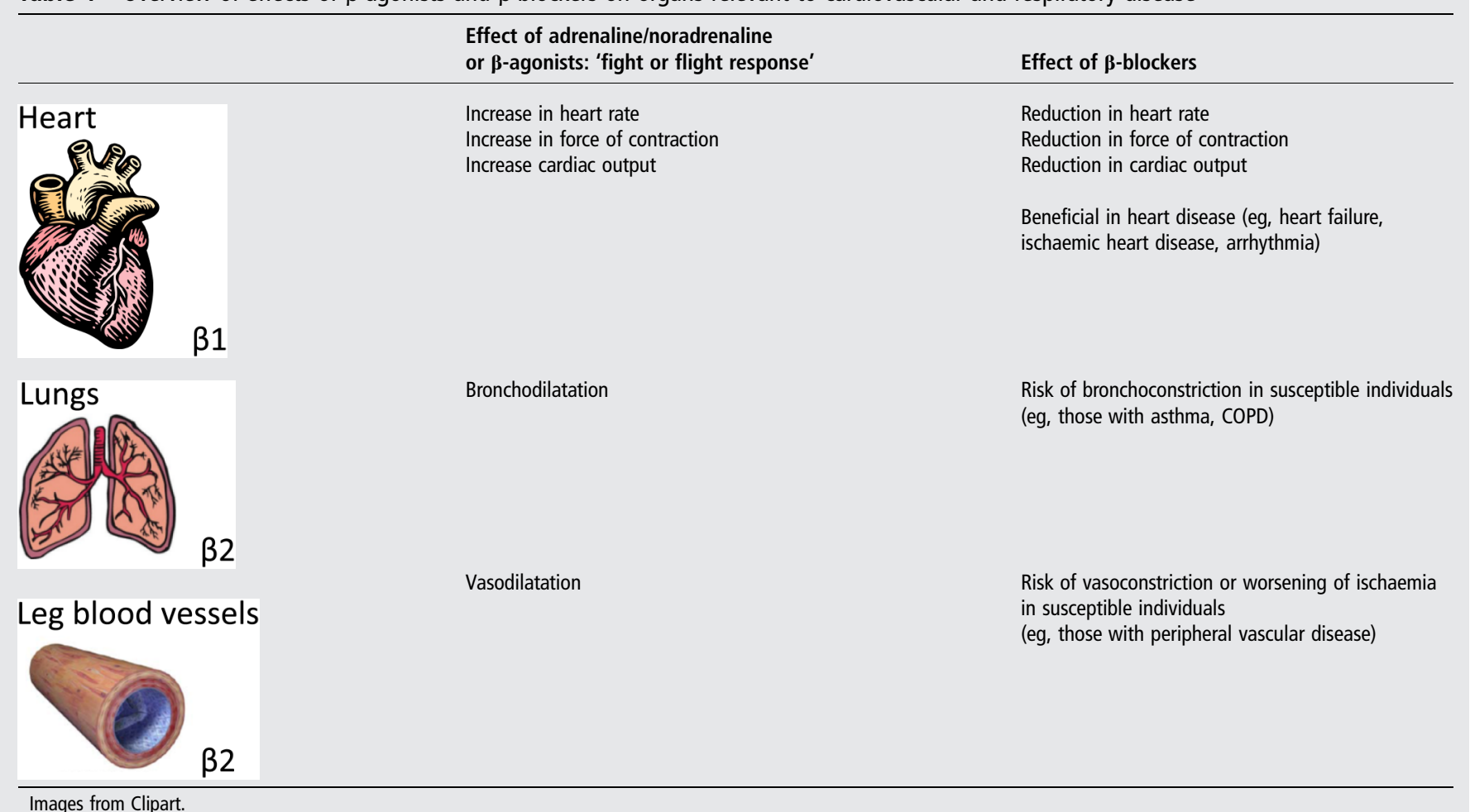


Table 2 Theoretical risks and benefits for those with heart disease and COPD treated with $\beta$-blockers (over and above the known cardiovascular benefits)

\section{Theoretical risks of}

$\beta$-blockers

Theoretical benefits of $\beta$-blockers

Reduction in basal lung function Reduction in efficacy of emergency rescue $\beta$-agonists

Reduction in efficacy of long-acting $\beta$-agonist

Concern over distinguishing COPD from asthma

Inhibition of cardiac stimulation by increased endogenous catecholamines during exacerbation

Inhibition of cardiac stimulation of $\beta$-agonists given during exacerbation

Potential reduction in systemic inflammation

propranolol and metoprolol. ${ }^{44} 45$ A study directly examining $\beta$-blocker tolerability in patients with concomitant heart disease and carefully documented airways disease, found that $\beta$-blockers were tolerated by $84 \%$ of the COPD patients (but only $50 \%$ with asthma). ${ }^{46}$

A complication of examining historical $\beta$-blocker studies for safety in obstructive airways disease is that many of the older studies used $\beta$-blockers that are no longer recommended. For example, $\beta$-blockers with ISA (ie, partial agonists ${ }^{41} 47{ }^{48}$ ) were thought to be beneficial because they would block the potentially harmful effect of high levels of catecholamines while providing a background increased sympathetic activation to maintain cardiac output and prevent bronchospasm. ${ }^{49}$ Clinical studies have since shown that $\beta$-blockers with agonist activity are not beneficial, and even detrimental, in cardiovascular therapy and so are no longer recommended. A Cochrane review concluded that $\beta$-blockers were safe in patients with COPD. ${ }^{50}$ However, 11 of the original 20 studies cited were one day, single-dose studies in patients with stable COPD. The remainder were of short duration ( 2 days to 12 weeks), and many studies used $\beta$-blockers with ISA that are not now recommended. Furthermore, the limitations listed by the authors included small sample size studies, $80 \%$ were male patients, randomisation was not always clear, some studies were only single blinded and some had no placebo controls.

To assess the safety of $\beta$-blockers in people with COPD, and particularly to assess their safety during exacerbations, longterm clinical studies are needed. Dorow et $a l^{51}$ studied the effects of bisoprolol and atenolol in 40 patients with COPD and angina in a double-blind cross-over study. They reported a $460 \mathrm{~mL} / \mathrm{min}$ reduction in peak expiratory flow rate (PEFR) following 6 months bisoprolol and a $270 \mathrm{~mL}$ reduction in PEFR with atenolol. They also showed that the decrease in $\mathrm{FEV}_{1}$ improved during the washout period after the $\beta$-blocker was stopped, suggesting the decline was treatment related rather than disease progression. Hawkins et $a l^{52}$ studied bisoprolol in patients with heart failure and COPD and found a $70 \mathrm{~mL}$ reduction in $\mathrm{FEV}_{1}$ with bisoprolol (14 patients), while a $120 \mathrm{~mL}$ increase in $\mathrm{FEV}_{1}$ with placebo (13 patients). They also assessed symptoms and concluded that 'despite the fall in $\mathrm{FEV}_{1}$, symptoms and quality of life were not impaired'. Another cross-over study looking at lung function in heart failure patients taking carvedilol, metoprolol and bisoprolol noted that the biggest reduction in lung function was in those taking the least $\beta 1$-selective $\beta$-blocker carvedilol. ${ }^{53}$

Thus, $\beta$-blockers are associated with a reduction of lung function $\left(\mathrm{FEV}_{1}\right)$ in the general population and in those with COPD, and the $\beta 1$-selectivity versus $\beta 2$-selectivity of the $\beta$-blocker used appears to play a part.
A recent study examined the effect of $\beta$-blockers on mortality in patients with severe, oxygen-dependent COPD. ${ }^{54}$ In this prospective study, which attempted to account for the immortal time bias $^{55}$ and immeasurable time bias ${ }^{56}$ suggested to be present in many other COPD and $\beta$-blocker studies, ${ }^{57}$ Ekström et al reported an increased mortality in patients with severe COPD taking $\beta$-blockers.

\section{THEORETICAL AND CLINICAL STUDY BENEFITS OF 及-BLOCKERS IN COPD}

There are several theoretical reasons why $\beta$-blockers could be protective in the COPD population (table 2). COPD and heart disease share environmental risk factors (smoking and pollution) and both share pathophysiological factors-high adrenergic activation and increased systemic inflammation. ${ }^{20} 5859$ A deterioration or exacerbation of either disease will increase both the adrenergic and inflammatory state, which could potentially worsen the other condition. Furthermore, $\beta$-adrenergic activation and immunomodulation are linked. ${ }^{60-62} \beta$-blockers have been shown to reduce cytokines in patients with heart failure ${ }^{63}$ and improve outcomes in sepsis. ${ }^{64}$ So, first, $\beta$-blockers may reduce the background risk of exacerbation of both COPD and heart disease by lowering both the background adrenergic and inflammatory states (which may include both systemic inflammation and organ-specific inflammation).

Second, during an exacerbation of COPD, there are yet higher circulating catecholamines. This increases the risk of myocardial ischaemia, tachycardias, deterioration in heart failure and hypertension (and therefore stroke risk). $\beta$-Blockers could counteract all of these endogenous exacerbation-associated cardiovascular risks.

Third, during an exacerbation of COPD, patients are treated with $\beta$-agonists (often nebulised salbutamol), which in themselves cause significant tachycardia. Salbutamol (especially when nebulised) is significantly systemically absorbed but this compound is also a poorly selective ligand ${ }^{41}$ and will cause activation of cardiac $\beta 1$-adrenoceptors. Treatment with $\beta 2$-agonists has been shown to precipitate $\mathrm{MI}$ and increase adverse cardiovascular events. ${ }^{65-68} \beta$-Blockade might also prevent this drug-induced cardiovascular risk.

There are several observational studies suggesting that $\beta$-blockers are effective in heart disease in people with COPD, the benefit outweighing the risk in terms of improved overall survival. Following an MI, Gottlieb et $a l^{69}$ noted a $40 \%$ reduction in mortality with $\beta$-blockers (in keeping with the later randomised controlled trials), for those with and those without COPD. Lower all-cause mortality was also observed in COPD patients post-MI by Quint et $a l^{70}$ (average follow-up 2.9 years) and Andell et $a l^{71}$ (average follow-up 2.8 years). Quint et al used data from the Myocardial Ischaemia National Audit Project and highlighted the ongoing uncertainty of prescribing $\beta$-blockers to patients with COPD, for only $38 \%$ were taking one of seven $\beta$-blockers on discharge, despite a very high uptake of other drugs for secondary prophylaxis. In another study in people with heart failure and COPD, patients taking $\beta$-blockers had less exacerbations and emergency room visits (although exacerbation here was taken as any change from the stable state, be that cardiovascular, respiratory or anything else). ${ }^{72}$

With regard to the general COPD population, observational studies have reported lower exacerbation rates and improved survival in patients with COPD and cardiovascular disease treated with $\beta$-blockers. ${ }^{73}$ Others also reported a decrease in COPD exacerbations, including in people with severe COPD and those on home oxygen (in contrast to the study by Ekström 
et $a l^{54}$ ), and that this benefit was only seen with $\beta$-blockers, not with ACE inhibitors or calcium channel blockers, suggesting there is something special about $\beta$-blockers that reduced exacerbations. ${ }^{75}$ This issue is to be further investigated in a placebocontrolled trial with metoprolol, ${ }^{76}$ which has a $\beta 1$-selectivity versus $\beta 2$-selectivity of twofold to sixfold. ${ }^{38-40}$

Giving $\beta$-blockers during exacerbations has also been reported as safe. Dransfield et $a l^{77}$ observed a lower mortality in inpatients with an acute exacerbation of COPD taking $\beta$-blockers than those not. Rutten et $a l^{78}$ noted an improved mortality in patients with 'acute bronchitis' (taken as a surrogate for COPD) taking 'cardioselective' $\beta$-blockers and calcium antagonists (but not for non-cardioselective $\beta$-blockers, ACE inhibitors or angiotension receptor blockers). In a study involving 35000 patients, Stefan et $a l^{79}$ observed no difference in mortality in those taking $\beta$-blockers admitted for an exacerbation of COPD (ie, $\beta$-blockers did not kill patients during the exacerbation), but neither did they observe the reduced mortality reported by Dransfield $e t a l^{77}$ nor Rutten $e t a l^{78}$ and non-selective $\beta$-blocker use was associated with an increase in readmissions.

However, before recommending prescribing $\beta$-blockers to all with a diagnosis of COPD and heart disease, it is important to remember that the above are all observational studies and therefore open to significant bias. ${ }^{57}$ The severity of, or specific diagnostic criteria for COPD, is not always known, $\beta$-blockers used are not always specified, prior or new events of angina and MI and specific causes of death are not always reported. There are no long-term randomised studies assessing cardiovascular prophylaxis with $\beta$-blockers in patients with a history of either angina or MI and COPD, which is where a large potential benefit lies. Thus, although there is plenty of observational evidence of a potential benefit in people with COPD and cardiovascular disease, conclusive evidence is lacking. Despite this crucial deficit, some argue that it would be unethical to withhold $\beta$-blockers, for example, after an MI, a view seemingly endorsed by the National Institute for Health and Care Excellence. $^{70} 80{ }^{81}$ However, we believe it is time to move on with randomised controlled trials to generate definite answers, and to define which groups benefit from which treatments and how long the treatment should be continued (particularly in the post-MI COPD cohort).

\section{CURRENT RECOMMENDATIONS AND MOVING FORWARD}

There are an estimated $>1.2$ million people in England alone with COPD and heart disease. ${ }^{2}$ Furthermore, given the smoking rates in Asia (eg, two-thirds of men in China smoke ${ }^{82}$ ), this is a growing global problem that needs to be addressed. Even if a small decrease in $\mathrm{FEV}_{1}$ does not impair quality of life, clinician anxiety and the need to ensure that absolutely no harm is caused (including the need for effective $\beta 2$-agonist rescue therapy during and acute exacerbation) is paramount in achieving better $\beta$-blockade for those who have COPD and concomitant heart disease. Furthermore, the difficulty in separating 'pure' COPD patients from those with asthma/COPD is not always easy and it is now recognised that there is significant overlap. $^{83}$

GOLD $^{84}$ recommends treating those with heart failure or ischaemic heart disease and COPD with $\beta$-blockers. Clearly, however, it is crucial to observe patients for worsening breathlessness and deterioration of spirometry despite this guidance, and review the patient and stop $\beta$-blocker treatment if needed. The current recommendation is therefore to use the most 'cardioselective' $\beta$-blockers currently available (eg, bisoprolol), starting at a low dose, whenever possible in patients with COPD in a 'try it and see' approach. ${ }^{20} 85$ The Scottish guidelines (SIGN 147 , also published this year) makes similar recommendations for those with 'COPD without significant reversible airways obstruction,' where there is 'no suitable alternative', and also recommends close monitoring for adverse effects (see Annex 4 of SIGN 147.). ${ }^{86}$ Likewise, limiting systemic exposure to $\beta$-agonists (eg, using $2.5 \mathrm{mg}$ nebulised salbutamol instead of $5 \mathrm{mg}$, and stopping nebulisers as soon as possible after the acute phase of an exacerbation) in those with COPD and heart disease would reduce the cardiovascular risk as much as possible. ${ }^{85}$ These recommendations, however, are not founded on wellconducted prospective randomised trials and does not extrapolate to patients with asthma, where $\beta$-blockers remain contraindicated.

Moving forward, to understand whether our current $\beta$-blockers are safe or indeed beneficial, we need large randomised placebo-controlled trials to truly explore whether the benefit for cardiovascular mortality and morbidity (and potential improvement in COPD morbidity) does indeed outweigh the potential mortality and morbidity from bronchospasm or reduction in benefit of both long-acting and short-acting $\beta$-agonists in COPD.

An alternative may be the further development and assessment of a truly $\beta 1$-selective $\beta$-blocker, one that has such poor affinity for the $\beta 2$-adrenoceptor that it could not cause any $\beta 2$-mediated bronchospasm. Such molecules have recently been synthesised (with $\beta 1$-selectivity vs $\beta 2$-selectivity of 500 -fold to 5000 -fold ${ }^{87}$ ) and have been proven to be orally bioavailable and highly $\beta 1$-selective in animals. Such a drug would circumnavigate the entire bronchospasm issue, yet still provide the wellproven cardiovascular $\beta$-blocker benefit. In addition to providing a safe way forward for those with COPD and heart disease, peripheral vascular disease or other conditions mentioned above, it would potentially extend the safe use of $\beta$-blockers to those who have heart disease and asthma.

Another alternative is to avoid $\beta 1$-adrenoceptor antagonists altogether. If their beneficial prophylactic effect is predominantly due to a reduction in heart rate, ${ }^{88} 89$ then other drugs with this effect might fulfil this role. Ivabradine is such a contender. This recently licensed drug reduces heart rate by blocking $\mathrm{I}_{f}$ sodium-potassium channels, expressed particularly in the sinoatrial node, without reducing the power of myocardial contractility, unlike $\beta$-blockers. In a large randomised controlled trial in patients with stable coronary artery disease and left ventricular systolic dysfunction $<40 \%$, ivabradine (in addition to standard therapy, ie, for many patients in addition to $\beta$-blockers) failed to reduce the primary end point of cardiovascular death, admission for new or worsening heart failure or MI, but it did establish its tolerability and a suggested benefit in those with an entry heart rate above $70 \mathrm{bpm} .{ }^{90}$ The SHIFT trial, in patients with stable systolic heart failure (left ventricular ejection fraction $\leq 35 \%$ ) and basal sinus rhythm $>70 \mathrm{bpm}$, suggested an improvement in heart failure (due to a reduction in heart rate) in those taking ivabridine in addition to standard therapy. ${ }^{91}$ Unfortunately, this benefit was not confirmed in a subsequent trial of patients with stable coronary artery disease without heart failure, in whom the addition of ivabridine reduced heart rate but not improve clinical outcomes. ${ }^{92}$

In the COPD arena, ivabradine has been demonstrated to lower heart rate without impairing lung function, ${ }^{93}$ and to reduce tachycardia after salbutamol inhalation. ${ }^{94}$ In a substudy of patients with COPD in the SHIFT (heart failure) trial, those randomised to ivabradine (in addition to routine $\beta$-blockers) derived similar relative reductions in cardiovascular events to 
patients with no COPD, albeit without statistical confirmation. ${ }^{95}$ So the role of ivabridine in safe and effective cardiovascular prophylaxis in patients with COPD is, like $\beta$-blockers, not yet established either alone or in combination.

\section{CONCLUSION}

Treating people with cardiovascular disease and COPD is a difficult everyday problem and the balance of doing good while doing no harm is one that causes significant clinician anxiety. $\beta$-Blockers save lives in people with heart disease, specifically postinfarction and with heart failure, but are associated with a reduction in lung function. Observational studies suggest that many patients with COPD appear to tolerate this. However, the final answers as to whether $\beta$-blockers can be safely given to patients with COPD en mass on a long-term basis, how much of a fall in $\mathrm{FEV}_{1}$ is significant, whether long-term $\beta$-blockade negates the beneficial effect of long-acting $\beta$-agonist and the balance between $\beta$-blockade and $\beta$-agonist rescue during exacerbations is uncertain. Randomised controlled trials in $\beta$-blocker-naïve patients are the only way to answer this question, and therefore give confidence to clinicians to prescribe $\beta$-blockers to those with COPD. Maybe, the potential of novel highly $\beta 1$-selective antagonists might provide the impetus to study this important clinical problem.

Funding JGB (principal investigator) and RGW (cardiology advisor) were both involved in a Wellcome Trust funded Seeding Drug Discovery Initiative 'Development of highly-selective $\beta 1$-adrenoceptor antagonists for therapeutic application in patients with concomitant cardiovascular and respiratory disorders', grant number 086039/Z/08/Z.

Competing interests None declared.

Provenance and peer review Commissioned; externally peer reviewed.

Data sharing statement Any further information about the novel highly $\beta 1$-selective $\beta$-blockers should be addressed to jillian.baker@nottingham.ac.uk.

\section{REFERENCES}

$1 \mathrm{BTS} / \mathrm{SIGN}$ British guideline on the management of asthma: a national guideline. September 2016.

2 Department of Health (UK). An outcomes strategy for chronic obstructive pulmonary disease (COPD) and asthma in England, 2011.

3 Rutten FH, Cramer MJ, Lammers JW, et al. Heart failure and chronic obstructive pulmonary disease: an ignored combination? Eur J Heart Fail 2006;8:706-11.

4 Valk MJ, Broekhuizen BD, Mosterd A, et al. COPD in patients with stable heart failure in the primary care setting. Int I Chron Obstruct Pulmon Dis 2015;10:1219-24.

5 Boudestein LC, Rutten FH, Cramer MJ, et al. The impact of concurrent heart failure on prognosis in patients with chronic obstructive pulmonary disease. Eur J Heart Fail 2009:11:1182-8.

6 Feary JR, Rodrigues LC, Smith CJ, et al. Prevalence of major comorbidities in subjects with COPD and incidence of myocardial infarction and stroke: a comprehensive analysis using data from primary care. Thorax 2010;65:956-62.

7 GOLD. Global strategy for the diagnosis, management, and prevention of chronic obstructive pulmonary disease, 2006.

8 Calverley PM, Burge PS, Spencer $S$, et al. Bronchodilator reversibility testing in chronic obstructive pulmonary disease. Thorax 2003;58:659-64.

9 Hanania NA, Celli BR, Donohue JF, et al. Bronchodilator reversibility in COPD. Chest 2011:140:1055-63.

10 Albert P, Agusti A, Edwards L, et al. Bronchodilator responsiveness as a phenotypic characteristic of established chronic obstructive pulmonary disease. Thorax 2012:67:701-8.

11 Cazzola M, MacNee W, Martinez FJ, et al., American Thoracic Society; European Respiratory Society Task Force on outcomes of COPD. Outcomes for COPD pharmacological trials: from lung function to biomarkers. Eur Respir $J$ 2008:31:416-69.

12 Bleecker ER, Emmett A, Crater G, et al. Lung function and symptom improvement with fluticasone propionate/salmeterol and ipratropium bromide/albuterol in COPD: response by beta-agonist reversibility. Pulm Pharmacol Ther 2008;21:682-8.

13 Mahler DA, Donohue JF, Barbee RA, et al. Efficacy of salmeterol xinafoate in the treatment of COPD. Chest 1999;115:957-65.

14 Geake JB, Dabscheck EJ, Wood-Baker R, et al. Indacaterol, a once-daily beta2-agonist, versus twice-daily beta 2 -agonists or placebo for chronic obstructive pulmonary disease. Cochrane Database Syst Rev 2015;1:CD010139.
15 Black JW, Duncan WA, Shanks RG. Comparison of some properties of pronethalol and propranolol. Br J Pharmacol Chemother 1965:25:577-91.

16 Cruickshank JM. Are we misunderstanding beta-blockers. Int J Cardiol 2007:120:10-27

17 Gundersen T. Secondary prevention after myocardial infarction: subgroup analysis of patients at risk in the Norwegian Timolol Multicenter Study. Clin Cardiol 1985;8:253-65

18 Ellison KE, Gandhi G. Optimising the use of beta-adrenoceptor antagonists in coronary artery disease. Drugs 2005;65:787-97.

19 Hollenberg NK. The role of $\beta$-blockers as a cornerstone of cardiovascular therapy. Am J Hypertens 2005;18:165S-8S.

20 Malerba M, Montuschi P, Radaeli A, et al. Role of beta-blockers in patients with COPD: current perspective. Drug Discov Today 2015:20:129-35.

21 MERIT-HF Study Group. Effect of metoprolol CR/XL in chronic heart failure: Metoprolol CR/XL Randomised Intervention Trial in Congestive Heart Failure (MERIT-HF). Lancet 1999;353:2001-7.

22 CIBIS-II Investigators and Committees. The Cardiac Insufficiency Bisoprolol Study II (CIBIS-II): a randomised trial. Lancet 1999;353:9-13.

23 Packer M, Fowler MB, Roecker EB, et al., for the Carvedilol Prospective Randomized Cumulative Survival (COPERNICUS) Study Group. Effect of Carvedilol on the Morbidity of Patients With Severe Chronic Heart Failure: Results of the Carvedilol Prospective Randomized Cumulative Survival (COPERNICUS) Study. Circulation 2002;106:2194-9.

24 Flather MD, Shibata MC, Coats AJ, et al., SENIORS Investigators. Randomized trial to determine the effect of nebivolol on mortality and cardiovascular hospital admission in elderly patients with heart failure (SENIORS). Eur Heart $J$ 2005;26:215-25

25 Beta-blocker Evaluation of Survival Trial Investigators (BEST). A trial of the beta-blocker bucindolol in patients with advanced chronic heart failure. $N$ Engl J Med 2001;344:1659-67.

26 Xamoterol in severe heart failure. The Xamoterol in Severe Heart Failure Study Group. Lancet 1990:336:1-6.

27 Norwegian Multicenter Study Group. Timolol-induced reduction in mortality and reinfarction in patients surviving acute myocardial infarction. $N$ Eng/ J Med 1981;304:801-7.

28 BHAT Beta-Blocker Heart Attack Study Group. A randomised trial of propranolol in patients with acute myocardial infarction. JAMA 1982;247:1707-14.

29 Hjalmarson A, Elmfeldt D, Herlitz J, et al. Effect on mortality of metoprolol in acute myocardial infarction. A double-blind randomised trial. Lancet 1981;2:823-7.

30 Wilcox RG, Rowley JM, Hampton JR, et al. Randomised placebo-controlled trial comparing oxprenolol with disopyramide phosphate in immediate treatment of suspected myocardial infarction. Lancet 1980;2:765-9.

31 Coronary Prevention Research Group. An early intervention secondary prevention study with oxprenolol following myocardial infarction. Eur Heart J 1981;2: 389-93.

32 Taylor SH, Silke B, Ebbutt A, et al. A long-term prevention study with oxprenolol in coronary heart disease. N Engl J Med 1982;307:1293-301.

33 Australian and Swedish Pindolol Study Group. The effect of pindolol on the two years mortality after complicated myocardial infarction. Eur Heart J 1983;4:367-75.

34 Bristow MR, Ginsburg R, Umans V, et al. $\beta 1$ - and $\beta$ 2-adrenergic-receptor subpopulations in nonfailing and failing human ventricular myocardium: coupling of both receptor subtypes to muscle contraction and selective $\beta$ 1-receptor down-regulation in heart failure. Circ Res 1986;59:297-309.

35 Buxton $\mathrm{BF}$, Jones $\mathrm{CR}$, Molenaar $\mathrm{P}$, et al. Characterization and autoradiographic localization of $\beta$-beta-adrenoceptor subtypes in human cardiac tissues. $\mathrm{Br} J$ Pharmacol 1987;92:299-310.

36 Lee $\mathrm{S}$, Schwinger RH, Brixius K. Genetically changed mice with chronic deficiency or overexpression of the $\beta$-beta-adrenoceptors - what can we learn for the therapy of heart failure? Pflugers Arch 2008:455:767-74.

37 Waldeck B. Beta-adrenoceptor agonists and asthma-100 years of development. Eur J Pharmacol 2002:445:1-12.

38 Smith C, Teitler M. Beta-blocker selectivity at cloned human beta 1- and beta 2-adrenoceptors. Cardiovasc Drugs Ther 1999;13:123-6.

39 Schnabel P, Maack C, Mies F, et al. Binding properties of beta-blockers at recombinant beta1-, beta2-, and beta3-adrenoceptors. J Cardiovasc Pharmacol 2000;36:466-71.

40 Baker JG. The selectivity of $\beta$-adrenoceptor antagonists at the $\beta 1, \beta 2$ and $\beta 3$ adrenoceptors. Br J Pharmacol 2005;144:317-22.

41 Baker JG. The selectivity of $\beta$-adrenoceptor agonists at the human $\beta 1, \beta 2$ and $\beta 3$ adrenoceptors. Br J Pharmacol 2010;160:148-61.

42 Lewis RV, Lofthouse C. Adverse reactions with beta-adrenoceptor blocking drugs. An update. Drug Safety 1993;9:272-9.

43 Loth DW, Brusselle GG, Lahousse L, et al. $\beta$-Adrenoceptor blockers and pulmonary function in the general population: the Rotterdam Study. Br J Clin Pharmacol 2014:77:190-200.

44 Clague HW, Ahmad D, Carruthers SG. Influence of cardioselectivity and respiratory disease on pulmonary responsiveness to beta-blockade. Eur J Clin Pharmacol $1984 ; 27: 517-23$ 
45 van der Woude HJ, Zaagsma J, Postma DS, et al. Detrimental effects of beta-blockers in COPD: a concern for nonselective beta-blockers. Chest 2005; 127:818-24.

46 Kotlyar E, Keogh AM, Macdonald PS, et al. Tolerability of carvedilol in patients with heart failure and concomitant chronic obstructive pulmonary disease or asthma. J Heart Lung Transplant 2002;21:1290-5.

47 Jasper JR, Michel MC, Insel PA. Molecular mechanism of beta-adrenergic receptor blockers with intrinsic sympathomimetic activity. FASEB J 1998:2:2891-4.

48 Baker JG, Kemp P, March J, et al. Predicting in vivo cardiovascular properties of $\beta$-blockers from cellular assays: a quantitative comparison of cellular and cardiovascular pharmacological responses. FASEB J 2011;25:4486-97.

49 Prichard BN. The second Lilly Prize Lecture, University of Newcastle, July 1977. $\beta$-Adrenergic receptor blockade in hypertension, past, present and future. $\mathrm{Br} J \mathrm{Clin}$ Pharmacol 1978;5:379-99.

50 Salpeter $\mathrm{S}$, Ormiston T, Salpeter E. Cardioselective beta-blockers for chronic obstructive pulmonary disease. Cochrane Database Syst Rev 2005;(4):CD003566.

51 Dorow $\mathrm{P}$, Thalhofer $\mathrm{S}$, Bethge $\mathrm{H}$, et al. Long-term treatment of angina pectoris with bisoprolol or atenolol in patients with chronic obstructive bronchitis: a randomized, double-blind crossover study. J Cardiovasc Pharmacol 1990;16(Suppl 5):S36-44.

52 Hawkins NM, MacDonald MR, Petrie MC, et al. Bisoprolol in patients with heart failure and moderate to severe chronic obstructive pulmonary disease: a randomized controlled trial. Eur J Heart Fail 2009;11:684-90.

53 Jabbour A, Macdonald PS, Keogh AM, et al. Differences between beta-blockers in patients with chronic heart failure and chronic obstructive pulmonary disease: a randomized crossover trial. J Am Coll Cardiol 2010;55:1780-7.

54 Ekström MP, Hermansson AB, Ström KE. Effects of cardiovascular drugs on mortality in severe chronic obstructive pulmonary disease. Am J Respir Crit Care Med 2013:187:715-20.

55 Suissa S. Immortal time bias in pharmaco-epidemiology. Am J Epidemiol 2008;167:492-9.

56 Suissa S. Immeasurable time bias in observational studies of drug effects on mortality. Am J Epidemiol 2008;168:329-35.

57 Suissa S, Ernst P. $\beta$-Blockers for COPD inpatients. Thorax 2012;67:936-7.

58 Libby P. Inflammation in atherosclerosis. Nature 2002;420:868-74.

59 Agustí A, Edwards LD, Rennard SI, et al. Evaluation of COPD Longitudinally to Identify Predictive Surrogate Endpoints (ECLIPSE) Investigators. Persistent systemic inflammation is associated with poor clinical outcomes in COPD: a novel phenotype. PLOS ONE 2012;7:e37483.

60 Elenkov IJ, Wilder RL, Chrousos GP, et al. The sympathetic nerve-an integrative interface between two supersystems: the brain and the immune system. Pharmacol Rev 2000;52:595-638.

61 Padro CJ, Sanders VM. Neuroendocrine regulation of inflammation. Semin Immunol 2014;26:357-68.

62 Hong $S$, Dimitrov $S$, Cheng $T$, et al. Beta-adrenergic receptor mediated inflammation control by monocytes is associated with blood pressure and risk factors for cardiovascular disease. Brain Behav Immun 2015;50:31-8.

63 Ohtsuka T, Hamada M, Hiasa G, et al. Effect of beta-blockers on circulating levels of inflammatory and anti-inflammatory cytokines in patients with dilated cardiomyopathy. J Am Coll Cardiol 2001;37:412-17.

64 Pemberton $\mathrm{P}$, Veenith $\mathrm{T}$, Snelson $\mathrm{C}$, et al. Is it time to beta block the septic patient? Biomed Res Int 2015;2015:424308.

$65 \mathrm{Au} \mathrm{DH}$, Curtis JR, Every NR, et al. Association between inhaled beta-agonists and the risk of unstable angina and myocardial infarction. Chest 2002;121:846-51.

66 Au DH, Lemaitre RN, Curtis JR, et al. The risk of myocardial infarction associated with inhaled beta-adrenoceptor agonists. Am J Respir Crit Care Med 2000;161(Pt 1):827-30.

67 Salpeter SR, Ormiston TM, Salpeter EE. Cardiovascular effects of beta-agonists in patients with asthma and COPD: a meta-analysis. Chest 2004;125:2309-21.

68 Macie C, Wooldrage K, Manfreda J, et al. Cardiovascular morbidity and the use of inhaled bronchodilators. Int J Chron Obstruct Pulmon Dis 2008;3:163-9.

69 Gottlieb SS, McCarter RJ, Vogel RA. Effect of beta-blockade on mortality among high-risk and low-risk patients after myocardial infarction. $N$ Engl J Med 1998;339:489-97.

70 Quint JK, Herrett E, Bhaskaran K, et al. Effect of $\beta$ blockers on mortality after myocardial infarction in adults with COPD: population based cohort study of UK electronic healthcare records. BMJ 2013;347:f6650.

71 Andell P, Erlinge D, Smith JG, et al. $\beta$-blocker use and mortality in COPD patients after myocardial infarction: a Swedish nationwide observational study. J Am Heart Assoc 2015;4. pii: e001611.
72 Puente-Maestu L, Calle M, Ortega-González A, et al., GEMEPOC Group. Multicentric study on the beta-blocker use and relation with exacerbations in COPD. Respir Med 2014;108:737-44.

73 Rutten FH, Zuithoff NP, Hak E, et al. Beta-blockers may reduce mortality and risk of exacerbations in patients with chronic obstructive pulmonary disease. Arch Intern Med 2010;170:880-7.

74 Farland MZ, Peters CJ, Williams JD, et al. $\beta$-Blocker use and incidence of chronic obstructive pulmonary disease exacerbations. Ann Pharmacother 2013;47:651-6.

75 Bhatt SP, Wells JM, Kinney GL, et al. $\beta$-Blockers are associated with a reduction in COPD exacerbations. Thorax 2016;71:8-14.

76 Bhatt SP, Connett JE, Voelker $\mathrm{H}$, et al. $\beta$-Blockers for the prevention of acute exacerbations of chronic obstructive pulmonary disease ( $\beta$ LOCK COPD): a randomised controlled study protocol. BMJ Open 2016;6:e012292.

77 Dransfield MT, Rowe SM, Johnson JE, et al. Use of beta blockers and the risk of death in hospitalised patients with acute exacerbations of COPD. Thorax 2008;63:301-5.

78 Rutten FH, Groenwold RH, Sachs AP, et al. $\beta$-Blockers and all-cause mortality in adults with episodes of acute bronchitis: an observational study. PLoS One 2013;8: e67122.

79 Stefan MS, Rothberg MB, Priya A, et al. Association between $\beta$-blocker therapy and outcomes in patients hospitalised with acute exacerbations of chronic obstructive lung disease with underlying ischaemic heart disease, heart failure or hypertension. Thorax 2012;67:977-84.

80 NICE. CG108 Chronic Heart Failure in Adults: management. 2010

81 NICE. CG172 Myocardial infarction: cardiac rehabilitation and prevention of further myocardial infarction. 2013.

82 Chen Z, Peto R, Zhou M, et al., China Kadoorie Biobank (CKB) Collaborative Group. Contrasting male and female trends in tobacco-attributed mortality in China: evidence from successive nationwide prospective cohort studies. Lancet 2015;386:1447-56.

83 Postma DS, Rabe KF. The asthma-COPD overlap syndrome. N Engl J Med 2015:373:1241-9.

84 GOLD. Global strategy for the diagnosis, management, and prevention of chronic obstructive pulmonary disease updated. 2016.

85 Hawkins NM, Petrie MC, Macdonald MR, et al. Heart failure and chronic obstructive pulmonary disease the quandary of beta-blockers and beta-agonists. J Am Coll Cardiol 2011;57:2127-38.

86 SIGN 147. Management of chronic heart failure. March 2016.

87 Baker JG, Fischer PM, Fromont C, et al. Novel ether linked compounds and improved treatments for cardiac and cardiovascular disease. University of Nottingham, UK. PCT Int Pat Appl Publ WO 2012104659. 2012.

88 Fox K, Ford I, Steg PG, et al., BEAUTIFUL investigators. Heart rate as a prognostic risk factor in patients with coronary artery disease and left-ventricular systolic dysfunction (BEAUTIFUL): a subgroup analysis of a randomised controlled trial. Lancet 2008;372:817-21.

89 Böhm M, Swedberg K, Komajda M, et al., SHIFT Investigators. Heart rate as a risk factor in chronic heart failure (SHIFT): the association between heart rate and outcomes in a randomised placebo-controlled trial. Lancet 2010;376: 886-94.

90 Fox K, Ford I, Steg PG, et al., BEAUTIFUL Investigators. Ivabradine for patients with stable coronary artery disease and left-ventricular systolic dysfunction (BEAUTIFUL): a randomised, double-blind, placebo-controlled trial. Lancet 2008;372: 807-16.

91 Swedberg K, Komajda M, Böhm M, et al., SHIFT Investigators. Ivabradine and outcomes in chronic heart failure (SHIFT): a randomised placebo-controlled study. Lancet 2010;376:875-85.

92 Fox K, Ford I, Steg PG, et al., SIGNIFY Investigators. Ivabradine in stable coronary artery disease without clinical heart failure. N Engl J Med 2014;371:1091-9.

93 Majewski S, Slomka S, Zielinska-Wyderkiewicz E, et al. Heart rate-lowering efficacy and respiratory safety of ivabradine in patients with obstructive airway disease: a randomized, double-blind, placebo-controlled, crossover study. Am J Cardiovasc Drugs 2012;12:179-88.

94 Zulkarneev R, Zagidullin N, Abdrahmanova G, et al. Ivabradine prevents heart rate acceleration in patients with chronic obstructive pulmonary disease and coronary heart disease after salbutamol inhalation. Pharmaceuticals (Basel) 2012;5:398-404.

95 Tavazzi L, Swedberg K, Komajda M, et al., SHIFT Investigators. Clinical profiles and outcomes in patients with chronic heart failure and chronic obstructive pulmonary disease: an efficacy and safety analysis of SHIFT study. Int I Cardiol 2013;170:182-8. 